\title{
Prevalence and factors correlated with hypertension secondary from obstructive sleep apnea
}

\author{
Sittichai Khamsai, ${ }^{1}$ Pawornwan Mahawarakorn, ${ }^{1}$ Panita Limpawattana, ${ }^{1}$ Jarin Chindaprasirt, ${ }^{1}$ \\ Wattana Sukeepaisarnjaroen, ${ }^{1}$ Songkwan Silaruks, ${ }^{1}$ Vichai Senthong, ${ }^{1}$ Bundit Sawunyavisuth, ${ }^{2}$ \\ Kittisak Sawanyawisuth ${ }^{1}$ \\ ${ }^{1}$ Department of Medicine, Faculty of Medicine; ${ }^{2}$ Department of Marketing, Faculty of Business Administration and \\ Accountancy, Khon Kaen University, Khon Kaen, Thailand
}

\begin{abstract}
Background In 2003, the JNC 7 reported obstructive sleep apnea (OSA) as a cause of secondary hypertension. The prevalence of OSA in hypertension ranges from 30-80\%. There are limited data on the prevalence and risk factors of OSA in hypertensive patients. This study thus aimed to evaluate prevalence and clinical predictors of obstructive sleep apnea (OSA) in these patients.

Methods: This was a cross-sectional study and conducted at the hypertension clinic at Khon Kaen University's Srinagarind Hospital, Thailand. We enrolled patients with hypertension treated at the clinic. OSA was defined as apnea-hypopnea index of 5 events/hour or over according to cardiopulmonary monitoring. Patients whose hypertension was due to any other causes were excluded. The prevalence of OSA was calculated and risk factors for OSA were analyzed using multivariate logistic regression.

Results: There were 726 hypertensive patients treated at the clinic. Out of those, $253(34.8 \%)$ were randomly studied and categorized as either non-OSA (147 patients, 58.1\%) or OSA (106 patients, 41.9\%). There were four independent factors associated with OSA-induced hypertension: age, sex, history of snoring, and history of headache. Headache had an adjusted odds ratio (95\% confidence interval) of 3.564 (95\% confidence interval of $1.510,8.411)$.

Conclusion: Age, male sex, history of snoring, and headache were independent predictors of hypertension caused by OSA.
\end{abstract}

Key words: Age; snoring; predictors; headache.

Correspondence: Kittisak Sawanyawisuth, MD, PhD, Department of Medicine, Faculty of Medicine, Khon Kaen University, Khon Kaen 40002, Thailand. Tel. +66.43.363664 - Fax: +66.43.348399. E-mail: kittisak@kku.ac.th

Contributions: SK, KS, study concept and design, manuscript drafting; BS, KS, statistical analyses performing; PM, PL, JC, WS, SS, VS, data interpretation, contribution to discussion. All authors reviewed the manuscript, read, and approved the final manuscript.

Conflict of interest: The Authors declare no conflict of interest.

Funding: None.

Availability of data and materials: Data are available upon request.

Ethics approval and consent to participate: All procedures performed in studies involving human participants were in accordance with the ethical standards of the institutional and/or national research committee and with the 1964 Helsinki declaration and its later amendments or comparable ethical standards. The study was reviewed and approved by the Khon Kaen University Ethics Committee of Human Research (no. HE541373).

Informed consent: Informed consent was waived due to retrospective study design according to the law of Thailand.

Consent for publication: Not applicable. 


\section{Introduction}

Obstructive sleep apnea (OSA) is a common disease. It is estimated that 936 million adults aged 30-69 years have mild to severe OSA [1]. A systematic review found that OSA may be found in $61.9 \%$ of patients with cardiovascular diseases [2]. The European Heart Association has also announced in 2016 that OSA is a strong risk factor for several major cardiovascular diseases such as hypertension, coronary artery disease, atrial fibrillation, stroke, and heart failure [3].

In 2003, the JNC 7 reported that OSA is a secondary cause of hypertension [4]. The prevalence of OSA in cases of hypertension ranges from $30-80 \%$ with an average of $50 \%$ [5]. Several risk factors are related to OSA such as obesity, age, and gender [6-8]. Men have a two to three times higher risk of suffering from OSA than women [9]. For every $10 \%$ increase in weight, risk for OSA increases six-fold $[10,11]$. These risk factors have not been studied in any particular population such as patients suffering from hypertension. Additionally, clinical factors predictive of OSA may be helpful to detect OSA in patients with hypertension in resourcelimited setting of polysomnography. This study aimed to evaluate the prevalence and risk factors for OSA in cases of hypertension.

\section{Methods}

This was a cross-sectional study conducted at Khon Kaen University's hypertension clinic in Khon Kaen, Thailand. The study period was from July to October, 2016. We enrolled adult patients diagnosed with hypertension who were treated at the clinic. Obstructive sleep apnea was defined as an apnea-hypopnea index (AHI) value of five events/hour or greater as measured using cardiopulmonary monitoring [12]. Patients with other causes of hypertension were excluded. We used a simple random sampling method to enroll patients from the clinic database. The cardiopulmonary monitoring device used in this study was the Alice PDX ambulatory test (Philips Respironics, USA). This device has been found to exhibit $94.4 \%$ agreement with standard polysomnography [13]. Severity of OSA was categorized as mild, moderate, or severe based on AHI of 5-14, 15-29, or 30 events/hour or over [12]. Scoring of apnea or hypopnea was made based on a previous report [13].

Baseline characters and physical signs of all eligible patients were studied and recorded. Data since the time of diagnosis of hypertension were retrospectively reviewed. Risk factors, symptoms, and complications of OSA were also evaluated. Risk factors of OSA included body mass index, neck circumference, and anatomical features such as Mallampati classification, macroglossia, toruses, tonsillar enlargement, retrognathia, history of tonsillectomy, and denture. Neck circumference was measured over the crico-thyroid junction. Macroglossia was identified by evidence of dentation marks on the lateral side of the tongue. Five main OSA symptoms were studied: history of snoring, apnea having been observed, morning headaches, unrefreshed sleep, and daytime sleepiness. Complications of OSA were also recorded including diabetes, stroke, coronary artery disease, heart failure, atrial fibrillation, and gastroesophageal reflux disease.

\section{Sample size calculation}

The average prevalence of OSA in cases of hypertension is $50 \%$ [5], while the prevalence of OSA in our hypertension clinic was $40 \%$ by a pilot study. Based on a $95 \%$ confidence interval and power of $90 \%$, the estimated sample size was 210 . With the $10 \%$ of missing data, the required sample size was 231 subjects.

\section{Statistical analysis}

Eligible patients were categorized into two groups: hypertensive patients with and without OSA. Baseline and clinical characteristics of both groups were compared by using descriptive statistics. When appropriate, a Wilcoxon rank sum/Student's $t$-test and Fisher's exact tests/chi-square test were applied to compare the differences between the two groups in terms of numbers and proportions, respectively. Univariate logistic regression analysis was applied to calculate the crude odds ratio (OR) of individual variables for OSA-induced hypertension. All clinically significant variables were included in subsequent multivariate logistic regression analysis. Analytical results were presented as crude OR, adjusted OR, and 95\% confidence intervals (CI). The goodness of fit of the multivariate logistic regression model was tested using the Hosmer-Lemeshow method. All data analysis was performed using STATA software version 10.1 (StataCorp LP, College Station, TX, USA).

\section{Results}

There were 726 hypertensive patients treated at the clinic. Out of those, $253(34.8 \%)$ were randomly studied and categorized as either non-OSA (147 patients, 58.1\%) or OSA (106 patients, $41.9 \%)$. Those with OSA had a median AHI of 22 events/hour ( $1^{\text {st }}$ $3^{\text {rd }}$ percentile of 10-40) with a median lowest oxygen saturation of $79 \%\left(1^{\text {st }}-3^{\text {rd }}\right.$ percentile of $\left.74-86\right)$. Percentages of mild, moderate, and severe OSA were $30.39 \%, 31.37 \%$, and $38.24 \%$, respectively.

Baseline characters and physical signs of both groups are shown in Tables 1 and 2, respectively. There were nine factors significantly different between the two groups in terms of baseline factors including age, sex, history of snoring, witnessed apnea, morning headaches, unrefreshing sleep, daytime sleepiness, history of coronary artery disease, and previous alcohol consumption (Table 1). In terms of physical signs, there were three factors in which the two groups differed significantly including diastolic blood pressure, macroglossia, and tonsillar enlargement (Table 2). The OSA group had higher proportions of macroglossia $(41.5 \% \mathrm{vs}$ $8.2 \% ; \mathrm{p}<0.001)$ and tonsillar enlargement $(11.3 \%$ vs $1.4 \%$; $\mathrm{p}$ 0.001) than the non-OSA group. The median diastolic blood pressure was also higher in the OSA group than in the non-OSA group (80 vs $76.5 \mathrm{mmHg}$ ). There were four independent factors associated with OSA-induced hypertension including age, sex, history of snoring, and history of morning headaches. The adjusted odds ratios ( $95 \%$ confidence interval) of these factors were as follows: age $=0.974(95 \%$ CI of $0.951,0.998)$, sex $=2.052(95 \% \mathrm{CI}$ of $1.072,3.926)$, history of snoring $=8.044(95 \%$ CI of 4.053 , $15.962)$, and history of morning headaches $=3.564(95 \% \mathrm{CI}$ of $1.510,8.411)$ as shown in Table 3. The Hosmer-Lemeshow chisquare of the model was $13.99(\mathrm{p}=0.082)$.

\section{Discussion}

This study shows new knowledge regarding predictors of OSA in hypertensive patients. Only age, sex, history of snoring, and history of morning headaches were independent risk factors for OSA in patients with hypertension. These predictors can be categorized as risk factors and symptoms of OSA. The first two factors are risk factors of OSA, while histories of snoring and morning headache are symptoms of OSA.

Generally, increasing age is a risk factor for OSA, but not for hypertensive patients in this study. An age increases of one year lowered the risk for OSA in hypertensive patients by $3 \%$ (Table 3 ). These results can be explained by the characteristics of the study 
population. The non-OSA hypertension group had an average age of 62.7 years (Table 1). OSA prevalence increased with age and was steady after the sixth decade of life $[1,14,15]$. Another explanation of younger age in the OSA group in this study is proportion of female patients. In a study of OSA patients with female ratio of
$21.8 \%$ found that female patients with OSA had significantly older age than male patients (48.4 vs 43.4 years; $p=0.004$ ) [16]. In this study, the OSA group had a proportion of female patients of $41.5 \%$ but the average age of female patients was not different from male patients (59.9 vs 58.2 years; $\mathrm{p}=0.349)$. These findings may result

Table 1. Baseline characters of hypertensive patients categorized by presence of obstructive sleep apnea (OSA).

\begin{tabular}{|c|c|c|c|}
\hline Factor & $\begin{array}{c}\text { Non OSA } \\
\mathrm{N}=147\end{array}$ & $\begin{array}{c}\text { OSA } \\
N=106\end{array}$ & $\mathbf{p}$ \\
\hline Male sex & $60(40.8)$ & $62(58.5)$ & 0.006 \\
\hline Median ( $1^{\text {st }-3}$ rd $\left.q u a r t i l e\right)$ age, years & $65(57-71)$ & $56(47-63)$ & $<0.001$ \\
\hline Median (1st_-3rd quartile) BMI, kg/m² & $25.7(23.0-27.7)$ & $30.5(26.5-35.0)$ & $<0.001$ \\
\hline Obesity & $33(22.45)$ & $54(50.94)$ & $<0.001$ \\
\hline Snoring & $36(24.5)$ & $83(78.3)$ & $<0.001$ \\
\hline Witnessed apnea & $9(6.1)$ & $42(31.1)$ & $<0.001$ \\
\hline Morning headaches* & $15(10.2)$ & $29(27.4)$ & $<0.001$ \\
\hline Unrefreshed sleep & $12(8.2)$ & $20(18.9)$ & 0.014 \\
\hline Daytime sleepiness & $24(16.3)$ & $20(18.9)$ & $<0.001$ \\
\hline Diabetes mellitus & $48(32.7)$ & $34(32.4)$ & 0.923 \\
\hline Stroke & $8(5.4)$ & $34(32.4)$ & 0.499 \\
\hline Coronary artery disease & $1(0.7)$ & $7(6.6)$ & 0.030 \\
\hline Heart failure & $4(2.7)$ & $2(1.9)$ & 0.669 \\
\hline Atrial fibrillation & $3(2.0)$ & $2(1.9)$ & 0.931 \\
\hline Gastroesophageal reflux disease & $27(18.4)$ & $30(28.3)$ & 0.064 \\
\hline Allergic rhinitis & $9(6.1)$ & $13(12.3)$ & 0.093 \\
\hline Previous smoking & $19(12.9)$ & $18(17)$ & 0.369 \\
\hline Previous alcohol consumption & $25(17.0)$ & $30(28.3)$ & 0.033 \\
\hline Current smoking & $8(5.4)$ & $5(4.7)$ & 0.797 \\
\hline Current alcohol consumption & $18(12.2)$ & $19(17.9)$ & 0.210 \\
\hline
\end{tabular}

*Excludes other causes such as medication or infection; data presented as number (percentage) unless indicated otherwise; BMI, body mass index.

Table 2. Physical signs of hypertensive patients categorized by presence of obstructive sleep apnea (OSA).

\begin{tabular}{|c|c|c|c|}
\hline Factors & $\begin{array}{c}\text { Non OSA } \\
N=147\end{array}$ & $\begin{array}{c}\text { OSA } \\
\mathrm{N}=106\end{array}$ & $\mathbf{p}$ \\
\hline Median ( $1^{\text {st }} 3^{\text {rd }}$ quartile $)$ SBP, $\mathrm{mmHg}$ & $142(130-151)$ & $140(129-151)$ & 0.827 \\
\hline Median ( $1^{\text {st }} 3^{\text {rd }}$ quartile) $\mathrm{DBP}, \mathrm{mmHg}$ & $77(69-84)$ & $82(72-90)$ & 0.004 \\
\hline Median ( $1^{\text {st }}-3^{\text {rd }}$ quartile) neck circumference, $\mathrm{cm}^{*}$ & $37.0(34.0-44.0)$ & $41.5(37.5-45.0)$ & 0.082 \\
\hline $\begin{array}{l}\text { Mallampati classification* } \\
\text { Class I } \\
\text { Class II } \\
\text { Class III } \\
\text { Class IV }\end{array}$ & $\begin{array}{c}2(5.9) \\
9(26.5) \\
18(52.9) \\
5(14.7)\end{array}$ & $\begin{array}{c}2(2.5) \\
31(38.8) \\
34(42.5) \\
13(16.3)\end{array}$ & 0.492 \\
\hline Macroglossia & $12(8.2)$ & $44(41.5)$ & $<0.001$ \\
\hline Torus palatinus & $7(4.8)$ & $11(10.4)$ & 0.135 \\
\hline Torus mandibularis & $5(3.4)$ & $1(0.9)$ & 0.406 \\
\hline Tonsillar enlargement & $2(1.4)$ & $12(11.3)$ & 0.001 \\
\hline Retrognathia & $4(2.7)$ & $8(7.5)$ & 0.131 \\
\hline Tonsillectomy & $1(0.7)$ & $1(0.9)$ & 0.999 \\
\hline Denture & $3(2.0)$ & $5(4.7)$ & 0.243 \\
\hline
\end{tabular}

Data presented as number (percentage) unless indicated otherwise; SBP, systolic blood pressure; DBP, diastolic blood pressure; BMI, body mass index; obesity defined by body mass index of $30 \mathrm{~kg} / \mathrm{m}^{2}$ or over; *indicated missing data. 
Table 3. Factors associated with obstructive sleep apnea in hypertensive patients according to logistic regression analysis.

\begin{tabular}{lcc} 
Factors & Unadjusted odds ratio $(\mathbf{9 5 \%}$ confidence interval) & Adjusted odds ratio (95\% confidence interval) \\
Age & $0.950(0.930,0.970)$ & $0.974(0.951,0.998)$ \\
Male sex & $2.043(1.230,3.394)$ & $2.052(1.072,3.926)$ \\
\hline History of snoring & $11.127(6.134,20.183)$ & $8.044(4.053,15.962)$ \\
History of morning headaches & $3.314(1.673,6.567)$ & $3.564(1.510,8.411)$ \\
\hline Daytime sleepiness & $4.752(2.661,8.488)$ & $1.633(0.785,3.398)$ \\
Body mass index & $1.037(0.995,1.080)$ & $0.995(0.977,1.014)$ \\
\hline Smoking & $0.860(0.273,2.706)$ & $0.488(0.107,2.212)$
\end{tabular}

in lower average age in the OSA group.

Male sex was still an independent risk factor for OSA in patients with hypertension with a similar adjusted odds ratio to that of the general population (Table 3) [2,9]. Another meta-analysis also found that OSA was related with hypertension in male subjects with OR of $1.698(95 \%$ CI of $1.319,2.077)$ which is comparable with adjusted OR in this study (1.953) as shown in Table 3 [17]. A history of snoring is a strong indicator for OSA in hypertensive patients as well as the general population. The risk of OSA was eight times greater in hypertensive patients with a history of snoring compared with non-snorer hypertensive patients [18-20].

Approximately $10-30 \%$ of patients with OSA experienced bifrontal, squeezing headaches without nausea or photophobia. The headaches could last for several hours on a daily basis [21]. OSA causes several events of intermittent hypoxemia during sleep resulting in increasing sympathetic nervous system activation leading to headaches [22]. Additionally, increased carbon dioxide levels during apneic events may result in cerebrovascular dilatation leading to headache as well [23]. Both mechanisms also lead to hypertension. From these mechanisms, patients with OSA may have both headaches and hypertension.

A clinical study found that morning headache was related to moderate to severe OSA with an adjusted OR of 2.00 (95\% CI of $1.03,3.85)$ and lowest oxygen saturation in REM sleep [24, 25]. Patients with OSA who had headaches also had lower oxygen saturation during REM sleep than those without headaches $(82 \%$ vs $84 \%$ ). In this study, there was no significant difference in severity of OSA or oxygen saturation in those with and without headache. The proportions of patients with mild, moderate, and severe OSA with headache were $38.71 \%, 31.25 \%$, and $17.95 \%(p=0.143)$ respectively, while median lowest oxygen saturation in those with and without headache was $79 \%$ and $80 \%$, respectively (p 0.740). Our results were similar to those of a study from Poland which found no correlation between morning headache and oxygen saturation or AHI [26]. However, morning headache was significantly associated with hypertension with an odds ratio of 1.25 (95\% CI of $1.06,1.46)$. These data may indicate that though morning headache is associated with hypertension in patients with OSA, the causes may be multifactorial. Finally, headache in patients with OSA may be related to sleep bruxism, which may be improved by using an oral appliance [27].

Daytime sleepiness was a significant factor for OSA in hypertensive patients according to univariate logistic analysis, but was no longer significant after adjustment for other factors (Table 3). The reason why sleepiness was not a significant factor in this study is that it is more common in severe cases of OSA [28]. OSA patients with severe daytime sleepiness had significantly higher AHI than those without daytime sleepiness (55.7 vs 36.6 events/h; $\mathrm{p}<0.0001)$. The median AHI in this study was only 22 events/hour. Also, daytime sleepiness may have several causes such as poor sleep hygiene or medications [29]. Therefore, it may not be directly related to OSA. Another study confirmed that daytime sleepiness was not related to resistant hypertension with adjusted OR of $1.00(95 \%$ CI of $0.91,1.10)$ [30].

Obesity is the main risk factor for OSA [1,2]. This study showed that higher body mass index was not an independent factor associated with OSA in hypertensive patients. Even though the average body mass index in the OSA group was significantly higher than in the non-OSA group in this study (30.9 vs $\left.27.5 \mathrm{~kg} / \mathrm{m}^{2}\right)$, it was not significant after adjusted with other factors. As previously reported, Chinese or Japanese patients with OSA had lower body mass index than Caucasians [31,32]. The average body mass index in Caucasian group was significantly higher than the Chinese group ( 30.7 vs $28.4 \mathrm{~kg} / \mathrm{m}^{2}$ : $\mathrm{p}=0.03$ ). Anyway, the Chinese patients had narrower airway space than the Caucasians including shorter cranial bases, maxilla, and mandible length. These findings may explain why elevated body mass index was not the significant clue for OSA in Asian hypertensive patients (Table 3).

There are some limitations to this study. It was conducted in a university hospital. The patients may have more complex conditions. Some data may be missing due to the retrospective nature of the data collection including Mallampati classification, neck circumference, diagnosis of chronic obstructive pulmonary disease, and sleep bruxism. Further studies may be required to confirm the results of this study such as in other ethnicities. Finally, this study did not study the effects of CPAP or other aspects of OSA $[33,34]$.

\section{Conclusions}

This study found a high prevalence of OSA in patients with hypertension. Physicians should pay attention on age, sex, history of snoring, and history of headaches in hypertensive patients in order to detect OSA. Body mass index was not a predictor for OSA associated with hypertension in this study population. 
13. Nilius G, Domanski U, Schroeder M, Franke KJ, Hogrebe A, Margarit L, et al. A randomized controlled trial to validate the Alice PDX ambulatory device. Nat Sci Sleep 2017;9:171-80.

The authors would like to thank Dr. Dylan Southard (USA) for his English language editing and Academic and Research Affair, Faculty of Medicine (GR64302),Khon Kaen University, Khon Kaen, Thailand.

\section{References}

1. Benjafield AV, Ayas NT, Eastwood PR, Heinzer R, Ip MSM, Morrell MJ, et al. Estimation of the global prevalence and burden of obstructive sleep apnoea: a literature-based analysis. Lancet Respir Med 2019;7:687-98.

2. Dong R, Dong Z, Liu H, Shi F, Du J. Prevalence, risk factors, outcomes, and treatment of obstructive sleep apnea in patients with cerebrovascular disease: A systematic review. J Stroke Cerebrovasc Dis 2018;27:1471-80.

3. Piepoli MF, Hoes AW, Agewall S, Albus C, Brotons C, Catapano AL, et al. 2016 European Guidelines on cardiovascular disease prevention in clinical practice: The Sixth Joint Task Force of the European Society of Cardiology and Other Societies on Cardiovascular Disease Prevention in Clinical Practice (constituted by representatives of 10 societies and by invited experts) Developed with the special contribution of the European Association for Cardiovascular Prevention \& Rehabilitation (EACPR). Eur Heart J 2016;37:2315-81.

4. Chobanian AV, Bakris GL, Black HR, Cushman WC, Green LA, Izzo JL Jr, et al. The Seventh Report of the Joint National Committee on Prevention, Detection, Evaluation, and Treatment of High Blood Pressure: the JNC 7 report. JAMA 2003;289:2560-72.

5. Patel AR, Patel AR, Singh S, Singh S, Khawaja I. The association of obstructive sleep apnea and hypertension. Cureus 2019; 11:e4858.

6. Sawanyawisuth K, Chindaprasirt J, Senthong V, Makarawate P, Limpawattana P, Domthong A, et al. Lower BMI is a predictor of obstructive sleep apnea in elderly Thai hypertensive patients. Sleep Breath 2013;17:1215-9.

7. Chirakalwasan N, Teerapraipruk B, Simon R, Hirunwiwatkul $\mathrm{P}$, Jaimchariyatam N, Desudchit $\mathrm{T}$, et al. Comparison of polysomnographic and clinical presentations and predictors for cardiovascular-related diseases between non-obese and obese obstructive sleep apnea among Asians. J Clin Sleep Med 2013;9:553-7.

8. Franklin KA, Lindberg E. Obstructive sleep apnea is a common disorder in the population-a review on the epidemiology of sleep apnea. J Thorac Dis 2015;7:1311-22.

9. Nigro CA, Dibur E, Borsini E, Malnis S, Ernst G, Bledel I, et al. The influence of gender on symptoms associated with obstructive sleep apnea. Sleep Breath 2018;22:683-93.

10. Johnson RF, Hansen A, Narayanan A, Yogesh A, Shah GB, Mitchell RB. Weight gain velocity as a predictor of severe obstructive sleep apnea among obese adolescents. Laryngoscope 2020;130:1339-42.

11. Narayanan A, Yogesh A, Mitchell RB, Johnson RF. Asthma and obesity as predictors of severe obstructive sleep apnea in an adolescent pediatric population. Laryngoscope 2020;130:812-7.

12. Sateia MJ. International classification of sleep disorders-third edition: highlights and modifications. Chest 2014;146:138794.

14. Senaratna CV, Perret JL, Lodge CJ, Lowe AJ, Campbell BE, Matheson MC, et al. Prevalence of obstructive sleep apnea in the general population: A systematic review. Sleep Med Rev 2017;34:70-81.

15. Lo Bue A, Salvaggio A, Insalaco G. Obstructive sleep apnea in developmental age. A narrative review. Eur J Pediatr 2020;179:357-65.

16. Zhou X, Zhou B, Li Z, Lu Q, Li S, Pu Z, Luo F. Gender differences of clinical and polysomnographic findings with obstructive sleep apnea syndrome. Sci Rep 2021;11:5938.

17. Hou H, Zhao Y, Yu W, Dong H, Xue X, Ding J, et al. Association of obstructive sleep apnea with hypertension: A systematic review and meta-analysis. J Glob Health 2018;8:010405.

18. Xiao M, Tang X, Zhang F, Zhou L, Bu X, Liu X, et al. Association between self-reported snoring and hypertension among Chinese Han population aged 30-79 in Chongqing, China. Environ Health Prev Med 2020;25:78.

19. Lee SK, Choi K, Chang YH, Kim J, Shin C. Increased risk for new-onset hypertension in midlife male snorers: The 14-year follow-up study. J Sleep Res 2019;28:e12757.

20. Silverberg DS, Oksenberg A. Are sleep-related breathing disorders important contributing factors to the production of essential hypertension? Curr Hypertens Rep 2001;3:209-15.

21. Russell MB, Kristiansen HA, Kværner KJ. Headache in sleep apnea syndrome: epidemiology and pathophysiology. Cephalalgia 2014;34:752-5.

22. Ferini-Strambi L, Lombardi GE, Marelli S, Galbiati A. Neurological deficits in obstructive sleep apnea. Curr Treat Options Neurol 2017;19:16.

23. Jordan J, Shannon JR, Diedrich A, Black B, Costa F, Robertson $\mathrm{D}$, et al. Interaction of carbon dioxide and sympathetic nervous system activity in the regulation of cerebral perfusion in humans. Hypertension 2000;36:383-8.

24. Earl DE, Lakhani SS, Loriaux DB, Spector AR. Predictors of moderate to severe obstructive sleep apnea: identification of sex differences. Sleep Breath 2019;23:1151-8.

25. KoÇ G, Metİn KM, AkÇay BD, KaradaŞ Ö, Sayin R, Yetkİn S. Relationship between apnea-hypopnea index and oxygen desaturation in REM-sleep period and morning headache in patients with obstructive sleep apnea syndrome. Noro Psikiyatr Ars 2019;57:294-8.

26. Spałka J, Kędzia K, Kuczyński W, Kudrycka A, Małolepsza A, Białasiewicz P, et al. Morning headache as an obstructive sleep apnea-related symptom among sleep clinic patients-A crosssection analysis. Brain Sci 2020;10:57.

27. Park JW, Mehta S, Fastlicht S, Lowe AA, Almeida FR. Changes in headache characteristics with oral appliance treatment for obstructive sleep apnea. Sci Rep 2021;11:2568.

28. Shao C, Qi H, Lang R, Yu B, Tang Y, Zhang L, et al. Clinical features and contributing factors of excessive daytime sleepiness in chinese obstructive sleep apnea patients: The role of comorbid symptoms and polysomnographic variables. Can Respir J 2019;2019:5476372.

29. Hein M, Mungo A, Hubain P, Loas G. Excessive daytime sleepiness in adolescents: current treatment strategies. Sleep Sci 2020;13:157-71.

30. Gus M, Gonçalves SC, Martinez D, de Abreu Silva EO, Moreira LB, Fuchs SC, et al. Risk for obstructive sleep apnea by Berlin Questionnaire, but not daytime sleepiness, is associated with resistant hypertension: a case-control study. Am J 
Hypertens 2008;21:832-5.

31. Lee RW, Vasudavan S, Hui DS, Prvan T, Petocz P, Darendeliler MA, et al. Differences in craniofacial structures and obesity in Caucasian and Chinese patients with obstructive sleep apnea. Sleep 2010;33:1075-80.

32. Genta PR, Marcondes BF, Danzi NJ, Lorenzi-Filho G. Ethnicity as a risk factor for obstructive sleep apnea: comparison of Japanese descendants and white males in São Paulo, Brazil. Braz J Med Biol Res 2008;41:728-33.
33. Sawunyavisuth B. What are predictors for a continuous positive airway pressure machine purchasing in obstructive sleep apnea patients? Asia Pac J Sci Technol 2018;23:APST-23-0310.

34. Kingkaew N, Antadech T. Cardiovascular risk factors and 10year CV risk scores in adults aged 30-70 years old in Amnat Charoen Province, Thailand. Asia Pac J Sci Technol 2019;24:APST-24-04-04.

Received for publication: 1 May 2021. Accepted for publication: 25 June 2021.

This work is licensed under a Creative Commons Attribution-NonCommercial 4.0 International License (CC BY-NC 4.0).

CCopyright: the Author(s), 2021

Licensee PAGEPress, Italy

Multidisciplinary Respiratory Medicine 2021; 16:777

doi:10.4081/mrm.2021.777 